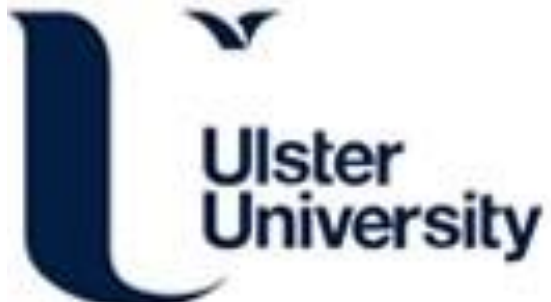

\section{Multilayered assembly of poly(vinylidene fluoride) and poly(methyl methacrylate) for achieving multi-shape memory effects}

Ji, X., Chen, D., Zheng, Y., Shen, J., Guo, S., \& Harkin-Jones, E. (2019). Multilayered assembly of poly(vinylidene fluoride) and poly(methyl methacrylate) for achieving multi-shape memory effects. Chemical Engineering Journal, 362, 190-198. https://doi.org/10.1016/j.cej.2019.01.016

Link to publication record in Ulster University Research Portal

\section{Published in:}

Chemical Engineering Journal

Publication Status:

Published (in print/issue): 15/04/2019

DOI:

10.1016/j.cej.2019.01.016

\section{Document Version}

Author Accepted version

\section{General rights}

Copyright for the publications made accessible via Ulster University's Research Portal is retained by the author(s) and / or other copyright owners and it is a condition of accessing these publications that users recognise and abide by the legal requirements associated with these rights.

\section{Take down policy}

The Research Portal is Ulster University's institutional repository that provides access to Ulster's research outputs. Every effort has been made to ensure that content in the Research Portal does not infringe any person's rights, or applicable UK laws. If you discover content in the Research Portal that you believe breaches copyright or violates any law, please contact pure-support@ulster.ac.uk. 


\section{Multilayered Assembly of Poly(Vinylidene Fluoride) and Poly(Methyl Methacrylate) for Achieving Multi-Shape Memory Effects}

Xiaoying Ji a, Dayong Chen ${ }^{\text {a }}$, Yu Zheng a, Jiabin Shen ${ }^{\text {a, }}$, Shaoyun Guo a, Eileen Harkin-Jones ${ }^{\text {a,b }}$

${ }^{\text {a }}$ State Key Laboratory of Polymer Materials Engineering, Polymer Research Institute of Sichuan University, Chengdu, Sichuan 610065, P. R. China

${ }^{\mathrm{b}}$ School of Engineering, University of Ulster, Newtownabbey, Antrim BT37 0QB, United Kingdom

*Corresponding author: shenjb@scu.edu.cn (J. Shen)

ABSTRACT: The alternately-organized poly(vinylidene fluoride) (PVDF)/ poly(methyl methacrylate) (PMMA) multilayer materials were prepared through layer-multiplying coextrusion. With the multiplication of layers, the thickness of each layer was reduced in proportion and the layer interfaces were enriched generating a broader and more continuous thermal transition temperature ( $\left.T_{\text {trans }}\right)$ from PVDF to PMMA layers as mapped by in-situ thermal analysis. The low- $\mathrm{T}_{\text {trans }}$ side originated from the glass transition of PMMA, whereas the high- $T_{\text {trans }}$ side was dominated by the melting of PVDF crystals based on the heating curves of DMA and DSC. The dielectric spectroscopy and 2D-SAXS were performed and demonstrated that the compositional diffusion not only broadened the relaxation distribution of amorphous 
chains, but also strengthened the interaction between amorphous and crystalline domains. Therefore, a unique multilayer network, where the crystals in PVDF layers acting as physical networks connected the neighboring amorphous layers, was fabricated and its potential application in obtaining multi-shape memory effect (MSME) was disclosed for the first time. The results exhibited that the 1024-layer specimen owned a better triple- and quadruple-shape memory capacity than conventional blend which possessed the same compositions and a similar $\mathrm{T}_{\text {trans }}$ range. The latter one even failed to successively memorize more than two temporary shapes. A possible mechanism was proposed through polarized IR and creeping-recovery measurements. Higher phase continuity which benefited for the stress transfer was revealed to play a significant role in strengthening the shape-fixing and -recovering ability during each shape-memory progress. Accordingly, a new physically-compounding strategy was addressed to achieve outstanding MSME for meeting complex demands in smart applications.

KEYWORDS: multi-shape memory effect; multilayer structure; phase continuity; interfacial diffusion. 
For Table of Contents use only

\section{Multilayered Assembly of Poly(Vinylidene Fluoride) and}

\section{Poly(Methyl Methacrylate) for Achieving Multi-Shape}

\section{Memory Effects}

Xiaoying Ji a, Dayong Chen a, Yu Zheng a, Jiabin Shen ${ }^{\text {a, }}$, Shaoyun Guo a, Eileen

Harkin-Jones ${ }^{b}$

${ }^{a}$ State Key Laboratory of Polymer Materials Engineering, Polymer Research Institute of Sichuan University, Chengdu, Sichuan 610065, P. R. China

b School of Engineering, University of Ulster, Newtownabbey, Antrim BT37 0QB, United Kingdom

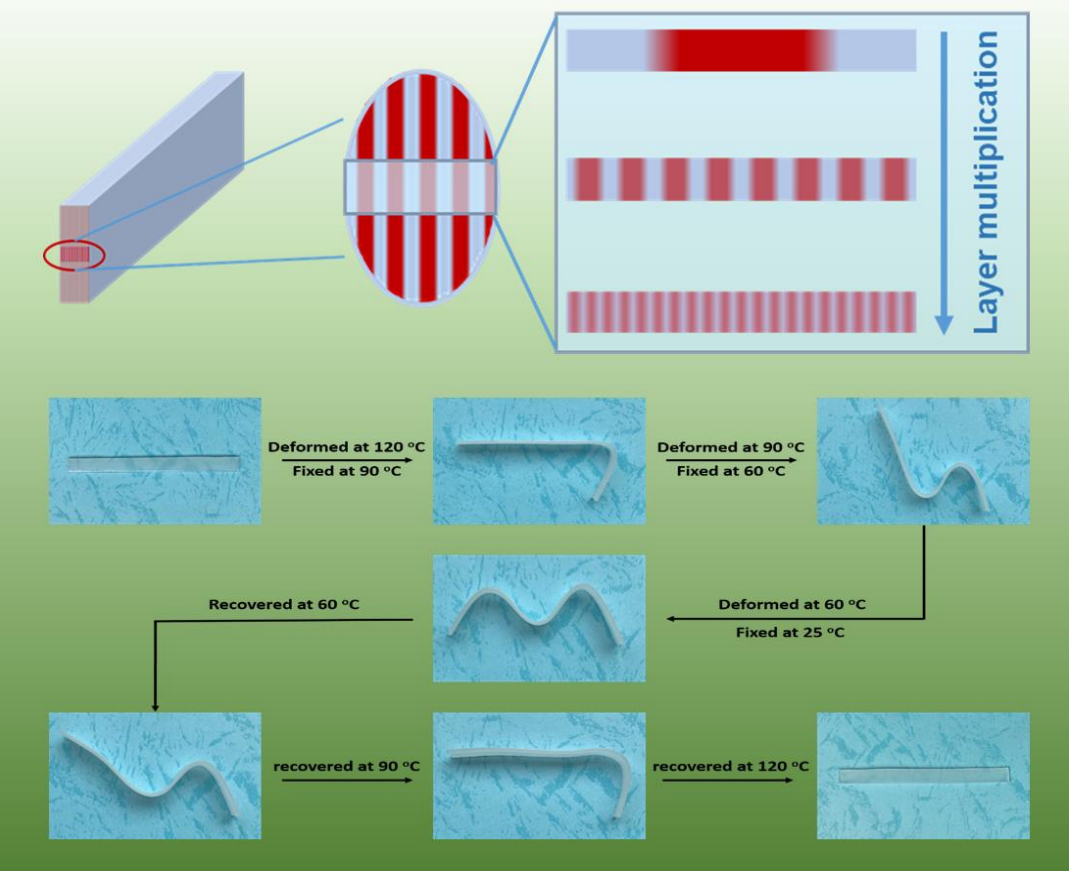




\section{INTRODUCTION}

Shape memory polymers (SMPs), as a class of stimuli-responsive materials, possess the ability to fix temporary deformation and sequentially recover to their original shape upon exposure to an external stimulus.[1, 2] Recently, increasing attention has been focused on developing tunable multi-shape memory polymers (MSMPs), which can memorize two or more temporary shapes in a preprogrammed cycle. This unique capability enables such materials to be applied in broader areas, ranging from aerospace deployable structures to smart fabrics and biomedical implants.[3-6]

Typically, most of MSMPs can be designed by introducing multiphase or multicomponent architecture, which owns multiple well-defined thermal transitions (e.g. glass transition[7, 8], melting transition[9, 10] or liquid crystalline transition[11]). As a rule, the maximum number of shapes those can be memorized correlates to the number of discrete transitions. Another strategy arises from a significant finding on Nafion, which possesses only one broad glass transition but exhibits at least quadruple-shape memory effect.[12] Based on this principle, the intermediate shapes of a MSMP can be finely tuned without introducing more compositions, representing a real advantage in robustness, recyclability and reuse of MSMPs.

To achieve multi-shape memory effect (MSME), numerous attentions are focused on broadening the thermal transition range by creating consecutive molecular relaxations through chemical grafting,[13] block copolymerization,[14] crosslinking,[15] and physical blending,[16] etc. For example, Luo et al. designed a 
compositional gradient copolymer by controlling the comonomer feed composition during copolymerization and demonstrated that this gradient transition has exhibits good MSME.[14] The domains with a high thermal transition temperature $\left(\mathrm{T}_{\text {trans }}\right)$ formed a physical network preventing chain relaxation, and the surrounding chains with a broad thermal transition held the temporary shapes and triggered shape recovery at different temperatures. Recently, a simple method was proposed by Samuel et al. A pair of miscible poly(L-lactide) (PLLA) and PMMA were physically blended by utilizing a traditional melt-processing technique.[16] In this blend, the crystals served as physical crosslinking points and a broad glass transition was obtained with the componential diffusion of amorphous regions, which finally yielded a good triple-shape memory property. However, limited by irregular phase separation and uncontrollable distribution of chain mobility, most blending systems are unfavorable for successively tuning the intermediate shapes in a wide temperature range due to the complex stress conditions involved in multi-shape programming. Also, the tortuous interfacial arrangement is detrimental to the stress transfer and energy conversion. Therefore, designing an optimum morphology is as important as broadening the glass transition, but few have been reported so far.

As a special co-continuous morphology, the multilayer structure is assembled by the parallel-distributed layers which has the highest phase continuity at any component ratio. Our previous work has demonstrated that parallel-distributed components are capable of maximizing their contribution to the shape fixing and recovering ability in a dual shape memory progress.[17] However, to memorized 
more temporary shapes, the previous-reported multilayered MSMPs were fabricated by introducing multiple well-defined thermal transitions, which means more components were required to achieve the multi-shape memory capacity.[10, 18] Actually, an intriguing aspect of the multilayer structures lies in the structural assembly perpendicular to the layer interfaces. As schematically illustrated in Figure 1, the compositions represented by red and blue colors can be regarded as alternately-organized "blocks" with different $\mathrm{T}_{\text {trans }}$ like that in block copolymers. By virtue of the interfacial diffusion effect, the gradient distribution of molecular mobility could be created around the layer interface and triggers the formation of a broad thermal transition, which has been applied to prepare damping materials with wide-temperature range.[19, 20] Thus, it can be reasonably supposed that such a particular architecture with high phase continuity and tunable thermal transition may possess a unique advantage in designing and preparing MSMPs.

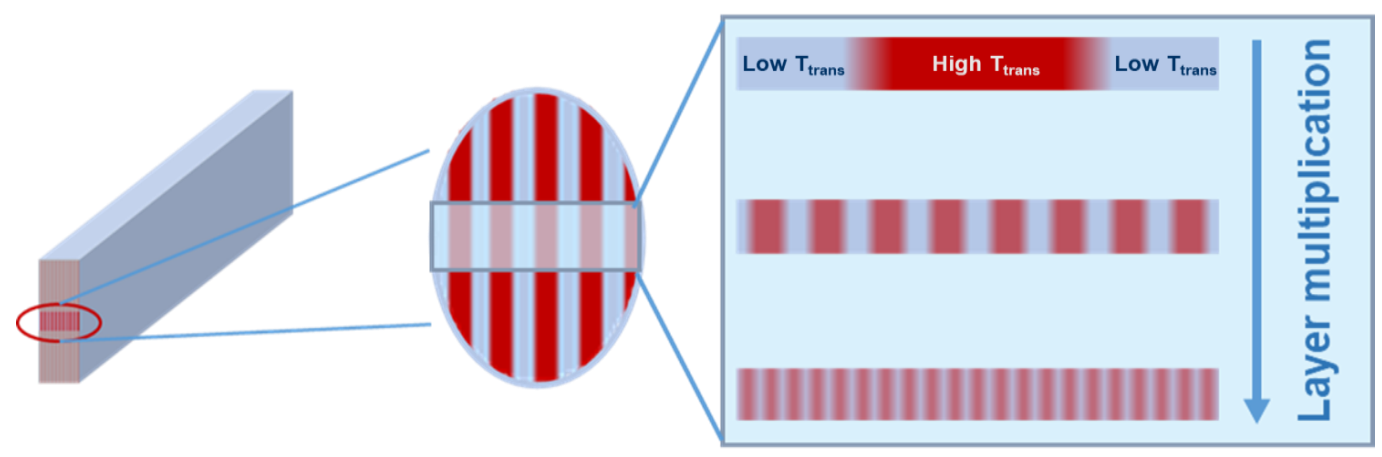

Figure 1. Schematic of the multilayer assembly of two compositions with high and low $\mathrm{T}_{\text {trans }}$ represented by red and blue colors, respectively.

To prove the proposition above, a multilayer material consisting of alternating layers of a commercial grade poly(vinylidene fluoride) (PVDF) and PMMA was 
prepared using layer-multiplying coextrusion technology[21-25]. The PVDF/PMMA compounding material was previously reported to have a potential application in ferroelectric-field transistor device or wastewater treatment membranes, [26, 27] but the MSME was less concerned because both of the components were not belonging to classic SMPs. As a pair of compatible polymers, PVDF and PMMA have a strong molecular interaction.[26, 28] Therefore, the development of their $\mathrm{T}_{\text {trans }}$ in the multilayer system was investigated with the multiplication of layers. To understand the origin of the broad $\mathrm{T}_{\text {trans, }}$, the interaction between amorphous and crystalline portions and its influence on the molecular relaxation were discussed. Ultimately, the advantages of the specific multilayer architecture in achieving MSME was revealed by performing triple- and quadruple-shape memory cycles and related mechanism was proposed.

\section{EXPERIMENTAL SECTION}

2.1. Materials. PVDF (Solef 6010) with a density of $1.78 \mathrm{~g} / \mathrm{cm}^{3}$ and a melt flow rate of $6.8 \mathrm{~g} / 10 \mathrm{~min}\left(230^{\circ} \mathrm{C} / 5 \mathrm{~kg}\right)$ was produced by Solvay Solexis. PMMA (CM207) resin with a density of $1.19 \mathrm{~g} / \mathrm{cm}^{3}$ and a melt flow rate of $8 \mathrm{~g} / 10 \mathrm{~min}\left(230^{\circ} \mathrm{C} / 3.8 \mathrm{~kg}\right)$ was provided by Taiwan Chimei. The materials are commercially available and used without further purification.

2.2. Sample Preparation. PVDF and PMMA pellets were coextruded using layer-multiplying coextrusion technology, the mechanism of which is described in Figure 2. The equipment consists of two single-screw extruders, a coextrusion block, several layer-multiplying elements (LMEs) and an exiting block. The PVDF and 
PMMA were extruded from different extruders respectively, and combined as a 2-layer melt in the coextrusion block, then flowed through a series of LMEs. In a LME, the melt was sliced into two left and right sections by a divider, and then recombined vertically leading to a doubling of the layer numbers. When $n$ LMEs were applied, a sheet with $2^{(\mathrm{n}+1)}$ layers could be produced. Finally, the multilayer melt was extruded from an exiting block. In this work, 16-, 128-, 256-, 512- and 1024-layer PVDF/PMMA were fabricated by applying 3, 6, 7, 8 and 9 LMEs, respectively. It is noteworthy that this coextrusion technology could fabricate the material with more layers, but the maximum layer numbers were chosen at 1024 to guarantee the layer integrity during the shape-memory cycles. By controlling the coextrusion speed, the total thickness of each extrudate was about $1.5 \mathrm{~mm}$, and the thickness ratio of PVDF and PMMA layers was maintained at around 2:1, irrespective of the layer numbers. However, the thickness of each layer would be reduced proportionally with the increase of layer numbers. Considering that the melt-extrusion process may induce some orientation in each extrudate, all extrudates were required to experience an annealing process at $200^{\circ} \mathrm{C}$ for $5 \mathrm{~min}$ to eliminate the thermal history before experiencing other tests. 


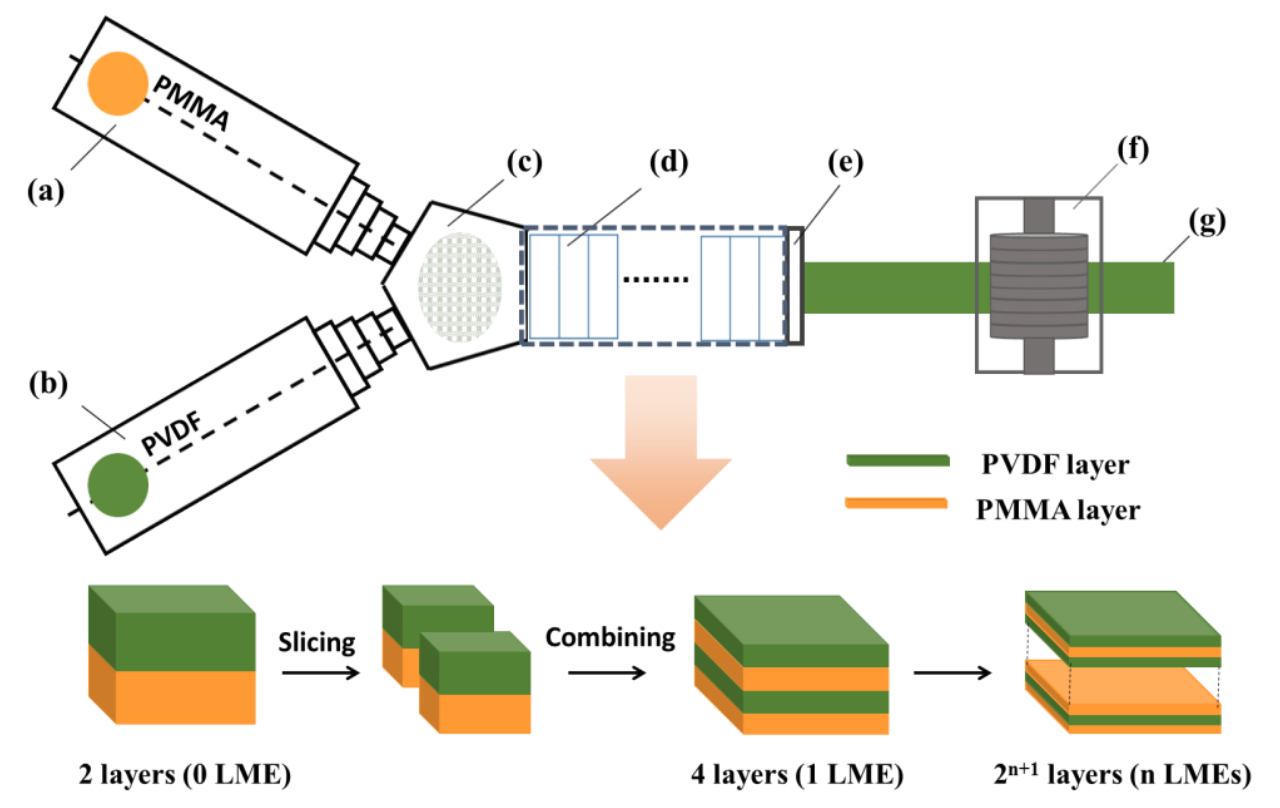

Figure 2. Schematic of layer-multiplying coextrusion system. (a and b) single screw extruder, (c) co-extrusion block, (d) layer-multiplying elements (LMEs), (e) exiting block, (f) rolling and cooling block, (g) extrudate with an alternating multilayer structure.

2.3. Morphological Observation. Atomic force microscope (AFM, Anasys Instruments, Santa Barbara, CA) was utilized to give a high resolution of the layer structure through the tapping mode. The AFM height image was $12 \mu \mathrm{m} \times 12 \mu \mathrm{m}$ and the scan rate was $1 \mathrm{~Hz}$. No additional image processing was performed, other than flattening.

2.4. Dynamic Mechanical Analysis (DMA). DMA analysis was carried out using a dynamic mechanical analyzer (Q800, TA Instrument, USA). The dimensions of each sample were $20 \mathrm{~mm}$ (length) $\times 4 \mathrm{~mm}$ (width) $\times 1.5 \mathrm{~mm}$ (thickness). The samples were heated at a heating rate of $3{ }^{\circ} \mathrm{C} / \mathrm{min}$ from -70 to $140{ }^{\circ} \mathrm{C}$ using the tension mode with a strain amplitude of $0.04 \%$. The testing frequency was maintained at $10 \mathrm{~Hz}$. 
2.5. Nano-Thermal Analysis (Nano-TA). The Nano-TA technique is a well-established local thermal analysis technique based on the afm+ system (Anasys Instruments, Santa Barbara, CA). Local thermal analysis was achieved using an AN2-200 $\mu \mathrm{m}$ Anasys ThermaLever probe to collect thermal transition and topological data on the nanoscale level. Prior to the experiments, the probe temperature was calibrated against standards with known melting points: poly( $\varepsilon$-caprolactone) (PCL, $\left.\mathrm{T}_{\mathrm{m}}=55^{\circ} \mathrm{C}\right)$, poly(ethylene) $\left(\mathrm{PE}, \mathrm{T}_{\mathrm{m}}=116{ }^{\circ} \mathrm{C}\right)$ and poly(ethylene terephthalate) (PET, $\mathrm{T}_{\mathrm{m}}=235^{\circ} \mathrm{C}$ ). During the measurements, the probe was heated from 40 to $180{ }^{\circ} \mathrm{C}$ by applying a fast speed of $2.5^{\circ} \mathrm{C} / \mathrm{s}$ in order to eliminate the influence of surrounding environment. The maximum deflection of the probe is defined as the thermal transition temperature of a spot (Figure S1). Collecting the transition temperature of all the spots, a visible transition temperature mapping is then obtained. The testing area was a two-dimensional space, covering $5 \mu \mathrm{m}$ (width) $\times 15 \mu \mathrm{m}$ (length) across the interface of the sample and keeping along the layer direction.

2.6. Broadband Dielectric Spectroscopy (BDS). Dielectric measurements were performed over a frequency range of $10-10^{6} \mathrm{~Hz}$ on a Novocontrol Concept 50 system with Alpha impedance analyzer and Quatro Cryosystem temperature control. The disk-shaped specimens of about $1.5 \mathrm{~mm}$ thickness were kept between two parallel electrodes of $20 \mathrm{~mm}$ diameter. BDS spectra were collected in a temperature range from -70 to $130{ }^{\circ} \mathrm{C}$ at $5{ }^{\circ} \mathrm{C}$ intervals.

2.7. Small-Angle X-ray Scattering (SAXS). SAXS measurements were performed using a Xeuss 2.0 system of Xenocs, France. A multilayer focused $\mathrm{Cu} \mathrm{K \alpha}$ 
X-ray source (GeniX3D Cu ULD, Xenocs SA, France, $\lambda=0.154 \mathrm{~nm}$ ) and scatterless collimating slits were used during the experiments. The sample-to-detector distance was $2500 \mathrm{~mm}$, providing scattering vector q range from 0.05 to $1.15 \mathrm{~nm}^{-1}$.

2.8. Shape Memory Characterization. The triple- and quadruple-shape memory experiments were carried out using the same DMA instrument with tension mode. The dimensions of the samples were approximately $20 \mathrm{~mm}$ (length) $\times 1.5 \mathrm{~mm}$ (width) $\times 0.6 \mathrm{~mm}$ (thickness). For the triple-shape memory experiment (Figure S2), the sample was firstly deformed $30 \%$ at $\mathrm{T}_{1}\left(115{ }^{\circ} \mathrm{C}\right)$ with a rate of $20 \% / \mathrm{min}$, then followed by cooling to $\mathrm{T}_{2}\left(70,65\right.$ or $\left.60{ }^{\circ} \mathrm{C}\right)$. Stress was removed for $10 \mathrm{~min}$ to obtain the temporary shape one. The second stretching was performed at $T_{2}$ to reach a final strain $60 \%$. After cooling to $30{ }^{\circ} \mathrm{C}$, the stress was again removed, achieving the second temporary shape. Finally, a free-strain recovery was conducted gradually by reheating to $T_{2}$ and $T_{1}$. The process for quadruple-shape memory characterization was similar. The related deformation temperatures were 120,90 and $60{ }^{\circ} \mathrm{C}$. Each MSME measurement was repeated three times under the same conditions.

The shape fixation ratio $\left(R_{f}\right)$ and recovery ratio $\left(R_{r}\right)$ in these processes were calculated using the following two equations:

$$
\begin{aligned}
& R_{f(m \rightarrow n)}=\frac{\varepsilon_{n}-\varepsilon_{m}}{\varepsilon_{n, \text { load }}-\varepsilon_{m}} \times 100 \% \\
& R_{r(n \rightarrow m)}=\frac{\varepsilon_{n}-\varepsilon_{m, r e c}}{\varepsilon_{n}-\varepsilon_{m}} \times 100 \%
\end{aligned}
$$

where $\mathrm{m}$ and $\mathrm{n}$ denote two different shapes, $\varepsilon_{\mathrm{m}}$ represents the original strain, $\varepsilon_{\mathrm{n}, \text { load }}$ is the target strain during the deforming procedure (from $m$ to $n$ ), $\varepsilon_{n}$ means the fixed strain after removing the stress, and the $\varepsilon_{\mathrm{m}, \mathrm{rec}}$ is the corresponding strain after shape 
recovery.

2.9. Polarized Infrared Spectroscopy. The molecular orientation under uniaxial stretching of multilayer and blend specimens was measured by the Thermo Nicolet iS10 Fourier-transform infrared spectroscopy (FTIR) spectrometer with a resolution of $2 \mathrm{~cm}^{-1}$ and an accumulation of 32 scans. The test slice samples with a thickness of about $30 \mu \mathrm{m}$ were cut by a rotary Microtome (YD-2508B) along the flow direction. In order to eliminate the effects of thermal history, the samples were firstly annealed at $200{ }^{\circ} \mathrm{C}$ for $5 \mathrm{~min}$. Then the slices were conducted uniaxial stretching by DMA Q800 under tension mode. The samples were deformed to $60 \%$ at $115{ }^{\circ} \mathrm{C}$ followed by a quenching to $25^{\circ} \mathrm{C}$, the temporary shape was obtained after removing the stress. Then the molecular orientation of the sample was recorded in the transmittance mode with a rotatable polarizer. Samples and backgrounds were twice accumulated from 550 to $1800 \mathrm{~cm}^{-1}$ with the polarizer at 0 and $90^{\circ}$ respectively.

The dichroic ratio $\mathrm{D}$ and Herman orientation function $\mathrm{f}$ can be obtained using the following equations:

$$
\begin{aligned}
& \mathrm{D}=\frac{A_{\|}}{A_{\perp}} \\
& \mathrm{f}=\frac{D-1}{D+2}
\end{aligned}
$$

where $\mathrm{A}_{\|}$and $\mathrm{A}_{\perp}$ are the areas of absorption peak parallel and perpendicular to the flow direction, respectively.

2.10. Creep-Recovery Test. The creeping behaviors of the 1024-layer and the blend specimens were performed using the same DMA instrument with tension mode. The procedure included following steps: (1) heating up to $80{ }^{\circ} \mathrm{C}$ and equilibrium for 5 
min; (2) imposing a constant external stress of $1 \mathrm{MPa}$ on each specimen for $40 \mathrm{~min}$; (3) recovering for another $30 \mathrm{~min}$ as removing the stress. During this process, the deforming strain of each specimen was recorded by the instrument.

\section{RESULTS AND DISCUSSION}

3.1. Microstructure and Distribution of $\mathbf{T}_{\text {trans. Based on the thickness scale of }}$ each layer, the microstructures of some as-extruded specimens were observed through AFM (Figure 3a) or PLM (Figure S3). It is clearly presented that the multilayer structure is well-defined even when the number of layers reaches 1024. The PVDF and PMMA layers are alternately assembled forming numerous parallel-distributed layer interfaces, which offers a regular architecture for tailoring the distribution of $\mathrm{T}_{\text {trans }}$ through the layer multiplication. In present study, an advanced AFM combined with a nano-thermal analysis technique (Nano-TA) was applied to in-situ track the $\mathrm{T}_{\text {trans }}$ around a layer interface.[29, 30] Figure 3b and Figure $\mathbf{S 1}$ describe the measuring procedure. The probe was locally heated on selected spots and the deflection of the cantilever was recorded. The temperature causing the maximum deflection was defined as the $\mathrm{T}_{\text {trans }}$ of that point.[30] Thus, the $\mathrm{T}_{\text {trans }}$ mapping of a rectangular domain was obtained by collecting the results of 90 spots and it clearly exhibited different patterns as the number of layers changes (Figure 3c). For the 16-layer specimen, there is a definite interface and the $\mathrm{T}_{\text {trans }}$ of two adjacent layers is easily distinguished by the colors. The high- $\mathrm{T}_{\text {trans }}$ side $\left(120 \sim 150{ }^{\circ} \mathrm{C}\right)$ corresponds to the PVDF layer and the low- $\mathrm{T}_{\text {trans }}$ side $\left(100 \sim 115^{\circ} \mathrm{C}\right)$ corresponds to the PMMA layer. 
It can be noted that the $T_{\text {trans }}$ close to the interface exhibits a comparatively lower value, which represents that interfacial diffusion or interaction may actuate the mobility of molecular chains. When the layer numbers reach 128 , a distinct $\mathrm{T}_{\text {trans }}$ reduction occurs on the PMMA side and this tendency is strengthened by further increasing the layers to 1024 . The $\mathrm{T}_{\text {trans }}$ in most parts of the PMMA layer is reduced below $80{ }^{\circ} \mathrm{C}$ with a minimum value approaching $60{ }^{\circ} \mathrm{C}$. This evidences that the $\mathrm{T}_{\text {trans }}$ can be effectively broadened through layer multiplication. Considering that the well-organized alternating layers have been proved by the microstructural images, the irregular interfaces appearing in the $\mathrm{T}_{\text {trans }}$ map might originate from a variation in molecular motions rather than from interlayer turbulence or component mixing.

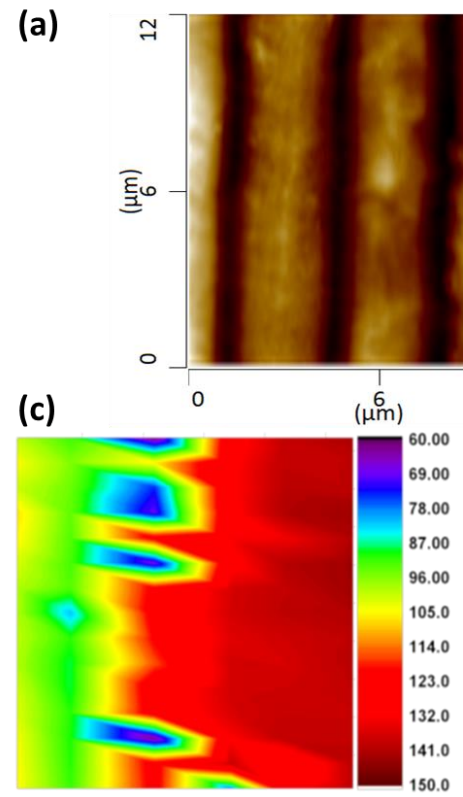

$16 \mathrm{~L}$
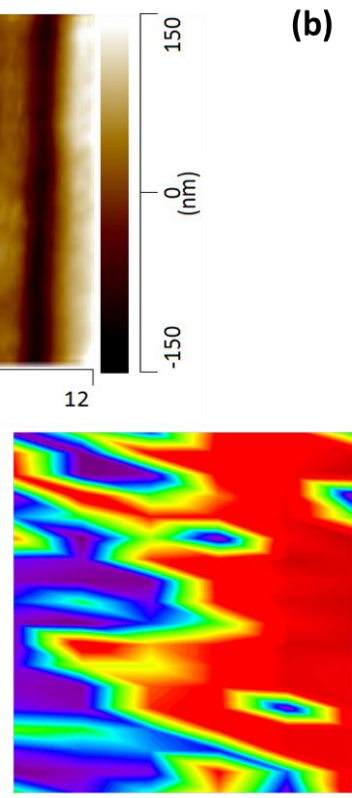

128L (b)

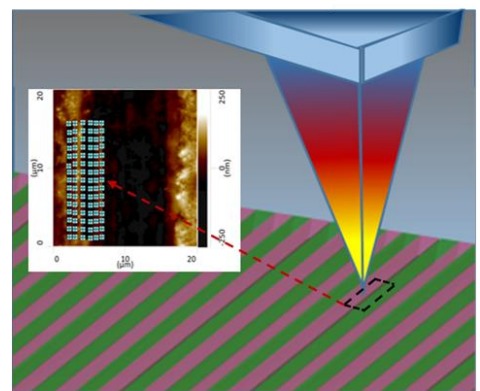

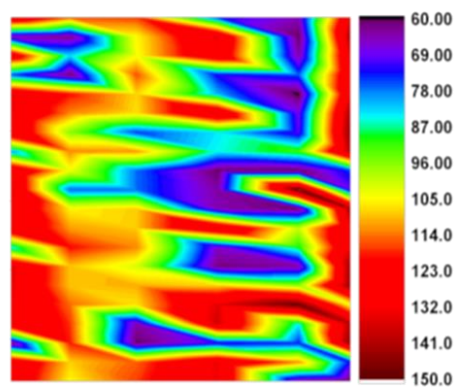

1024L

Figure 3. (a) AFM height image of 1024-layer PVDF/PMMA specimen using tapping mode; (b) Illustration of the Nano-TA measurement performed on a multilayer specimen (the insert micrograph is the height image of a specimen where a domain with $5 \mu \mathrm{m}$ (width) $\times 15 \mu \mathrm{m}$ (length) around an interface was chosen to test the $\mathrm{T}_{\text {trans }}$, 
the blue spots are the testing points); (c) The $\mathrm{T}_{\text {trans }}$ mapping of 16-, 128- and 1024-layer PVDF/PMMA specimens obtained through an AFM instrument combining Nano-TA technique.

3.2. Origin of Broad $\mathbf{T}_{\text {trans. }}$ With regard to the amorphous PMMA side, the variation of $\mathrm{T}_{\text {trans }}$ should be dominated by its glass transition temperature ( $\mathrm{T}_{\mathrm{g}}$, PMMA). Hence, the loss factor of the specimens with different layers as a function of temperature are compared in Figure 4a (the related storage modulus spectra is also supplied in Figure S4) and some corresponding results are given in Table 1. These spectra exhibit two glass transition peaks: The one appearing on the high-temperature side corresponds to the $T_{g, P M M A}$ and the other corresponds to the $T_{g}$ of the PVDF layer ( $\left.\mathrm{T}_{\mathrm{g}, \mathrm{PVDF}}\right)$. With increasing the layer numbers, the loss peak of PVDF gradually weakened and the one related to PMMA tended to move towards lower temperature together with increased broadness and sharply reduced storage modulus, which were commonly ascribed to the plasticizing effect of non-crystalline PVDF chains. $[28,31]$ When the layer numbers reached 1024, the thermal transition range is greatly expanded and even gets close to that of the blend specimen with the same compositions (Figure S5) due to the interfacial diffusion. For 1024-layer specimen, the $\mathrm{T}_{\mathrm{g} \text {,PMMA }}$ approached to $86^{\circ} \mathrm{C}$ and its full width at half maximum (FWHM) was as high as $63^{\circ} \mathrm{C}$, in contrast to the 16-layer specimen which had values of 121 and $26^{\circ} \mathrm{C}$. This trend is basically in agreement with that of the $\mathrm{T}_{\text {trans }}$ map in PMMA side. On the other hand, PVDF had a much lower $\mathrm{T}_{\mathrm{g}}$ than PMMA, but its segmental motion would 
be restrained by crystalline regions which have a high melting temperature $\left(T_{m}\right)$. Thus, it is reasonable that the $T_{\text {trans }}$ of PVDF layers is much larger than that of PMMA layers. Figure 4b shows the heating scans of a series of multilayer systems with the corresponding $\mathrm{T}_{\mathrm{m}}$ and crystallinity $\left(\mathrm{X}_{\mathrm{c}}\right)$ listed in Table $\mathbf{1}$. When the layer numbers were increased from 16 to 1024 , the $\mathrm{T}_{\mathrm{m}}$ was reduced by $3.2{ }^{\circ} \mathrm{C}$ and the $\mathrm{X}_{\mathrm{c}}$ also presented a slight reduction. The suppression of the crystallization suggests a potential influence originating from the enriched interfaces between PVDF and PMMA layers with the layer multiplication.
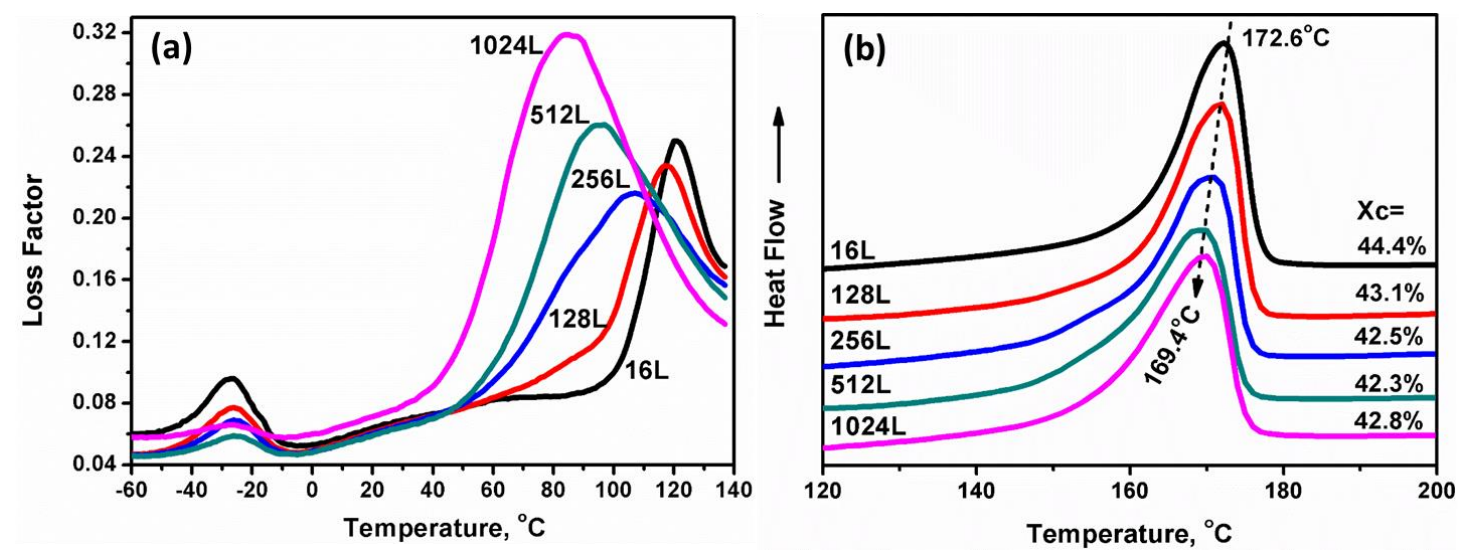

Figure 4. Spectra of 16-, 128-, 256-, 512- and 1024-layer PVDF/PMMA specimens as a function of temperature, measured through (a) DMA (heating rate: $3{ }^{\circ} \mathrm{C} / \mathrm{min}$ ) and (b) DSC (heating rate: $10^{\circ} \mathrm{C} / \mathrm{min}$ ).

Table 1. The $T_{g, P M M A}, F W H M, T_{m}$ and $X_{c}$ of 16-, 128-, 256-, 512- and 1024-layer PVDF/PMMA specimens obtained from DMA and DSC spectra. 


\begin{tabular}{ccccc}
\hline Samples & $\mathrm{T}_{\mathrm{g}, \mathrm{PMMA}}\left({ }^{\circ} \mathrm{C}\right)$ & $\mathrm{FWHM}\left({ }^{\circ} \mathrm{C}\right)$ & $\mathrm{T}_{\mathrm{m}}\left({ }^{\circ} \mathrm{C}\right)$ & $\mathrm{Xc}(\%)$ \\
\hline 16 layers & 121.5 & 29 & 172.6 & 44.4 \\
128 layers & 117.6 & 40 & 171.7 & 43.1 \\
256 layers & 106.9 & 55 & 170.5 & 42.5 \\
512 layers & 95.5 & 58 & 169.2 & 42.3 \\
1024 layers & 86.5 & 63 & 169.4 & 42.8 \\
\hline
\end{tabular}

3.3. Compositional Interaction. The neat PVDF and PMMA as well as their 16-, 128- and 1024-layer specimens were chosen to perform the BDS measurement, which was widely recognized as one of helpful methods to understand the compositional interaction from the viewpoint of the molecular relaxation[31, 32]. The test temperature was $80{ }^{\circ} \mathrm{C}$ and the frequency was in the range of $10-10^{6} \mathrm{~Hz}$, because the relaxation of the amorphous portions within the crystalline phase of PVDF $\left(\alpha_{\mathrm{c}, \text { PVDF}}\right)$ and the localized motions in the side groups of PMMA ( $\left.\beta_{\mathrm{PMMA}}\right)$ may appear distinguishable in terms of previous studies.[33, 34] As shown in Figure 5a, all multilayer specimens exhibit a single relaxation peak located intermediately between $\alpha_{c, P V D F}$ and $\beta_{\text {PMMA }}$. Since the neat polymers were combined layer-by-layer, the present system could be approximately regarded as a multilayer-assembled capacitor and its theoretical permittivity was simply calculated in accordance with a "series model".[35] It can be observed that the peak profile and the position of the theoretical curve are basically in agreement with the measured result for the 16-layer specimen, which indicates that the relaxation peak is component-dependent when there are several layers. However, the layer multiplication induced a deviation toward the high-frequency side. To quantitatively describe the development of these relaxation 
peaks, all experimental curves were fitted using the Havriliak-Negami (HN) empirical equation[16].

$\varepsilon^{*}(\omega)=\varepsilon_{\infty}+\frac{\Delta \varepsilon}{\left[1+\left(i \omega \tau_{H N}\right)^{\alpha}\right]^{\beta}}=\varepsilon^{\prime}-i \varepsilon^{\prime \prime}$

where, $\varepsilon^{*}$ is the complex dielectric permittivity, $\Delta \varepsilon$ is the dielectric strength, $\omega$ is the angular frequency, $\tau_{\mathrm{HN}}$ is the characteristic relaxation time, $\alpha$ and $\beta(0<\alpha, \alpha \beta<1)$ are defined as the symmetry and asymmetry shape parameters representing the relaxation time distribution. All fitting curves are plotted in Figure 3a and basically overlap with the corresponding experimental points. $\alpha$ and $\tau_{\mathrm{HN}}$ values are collected and compared in Table 2. It can be noted that the layer multiplication causes each parameter value to approach that of neat PMMA, which signifies that the $\alpha_{\mathrm{c}, \text { PVDF }}$ tends to be suppressed with the increase of layer interfaces. In order to further detect the influence of interfacial diffusion on the relaxation of PVDF molecules, SAXS was carried out and the normalized Lorentz-corrected Kratky plots $\left(I(q) * q^{2}\right.$ versus $\left.q\right)$ for neat PVDF and the 16-, 128-, 1024-layer PVDF/PMMA specimens are shown in Figure 5b. The long period representing the average thickness of the interlamellar spacing (L) within the PVDF crystals can be obtained from the following equation,

$\mathrm{L}=2 \pi / \mathrm{q}_{\max }$

where $\mathrm{q}_{\max }$ is the location of each scattering peak. The results listed in Table $\mathbf{2}$ clearly show that the specimens with more interfaces exhibits a larger $\mathrm{L}$ value, which is commonly ascribed to the incorporation of more PMMA chains into the interlamellar and interspherulitic regions during the crystallization of PVDF.[34, 36, 37] Accordingly, a distinct multilayer structure is generated as illustrated in Figure 3c. 
The compositional diffusion occurring around the layer interfaces strengthens the interaction between adjacent PVDF and PMMA "blocks" and causes a broad distribution of chain mobility. Like that in block copolymers, the PVDF crystals with higher $\mathrm{T}_{\text {trans }}$ would act as physical networks connecting the surrounding amorphous chains with a broad $\mathrm{T}_{\text {trans, }}$ which is regarded as a favorable architecture for MSMPs.

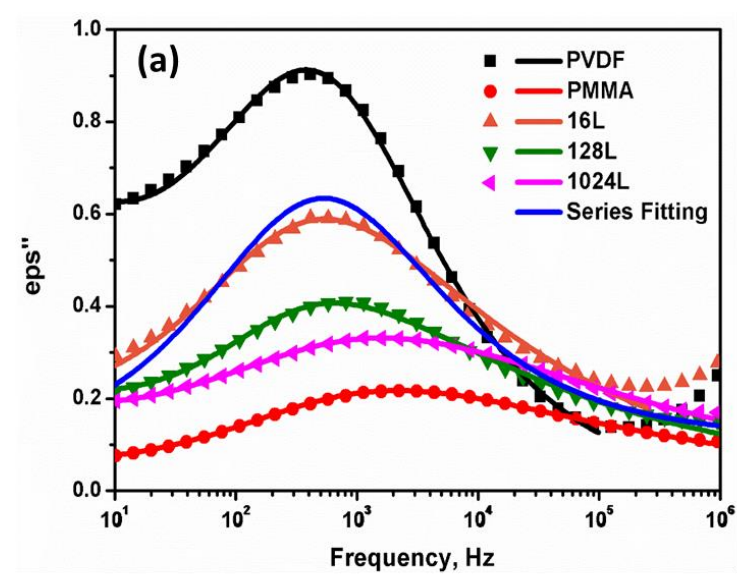

(c)

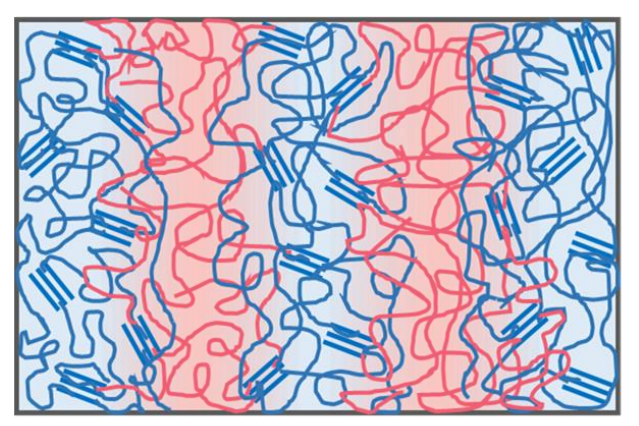

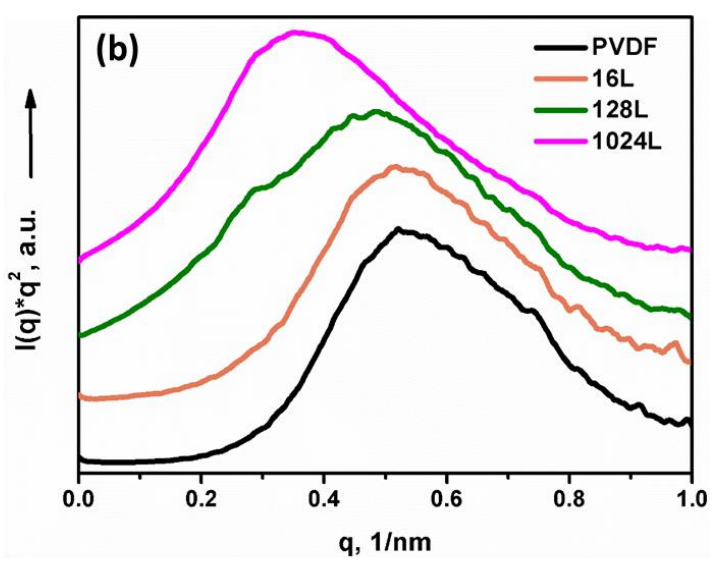

$\equiv$ Crystalline domains of PVDF

\section{Molecular chains of} amorphous PVDF

\section{Molecular chains of PMMA}

Figure 5. (a) Dielectric loss (eps") spectra of neat PVDF and PMMA as well as their 16-, 128- and 1024-layer specimens measured at $80^{\circ} \mathrm{C}$ and in the range of $10-10^{6} \mathrm{~Hz}$ (solid dots and lines represent measured results and fitting curves, respectively.); (b) Lorentz-corrected scattering intensity profiles of neat PVDF and 16-, 128-, 1024-layer specimens; (c) Schematic of potential microstructure originated from the interfacial diffusion in PVDF/PMMA multilayer specimens. 
Table 2. Havriliak-Negami relaxation time $\left(\tau_{\mathrm{HN}}\right)$ and shape parameter $(\alpha)$ obtained from BDS results; the $q_{\max }$ and $L$ values of obtained from 2D-SAXS.

\begin{tabular}{ccccc}
\hline Samples & $\tau_{\text {HN }}(\mathrm{s})$ & $\alpha$ & $q_{\max }(1 / n m)$ & L $(\mathbf{n m})$ \\
\hline PVDF & $4.8 E-4$ & 0.67 & 0.54 & 11.64 \\
16 layers & $3.4 E-4$ & 0.79 & 0.52 & 12.08 \\
128 layers & $2.3 E-4$ & 0.73 & 0.48 & 13.09 \\
1024 layers & $8.1 E-5$ & 0.42 & 0.36 & 17.45 \\
PMMA & $5.6 E-5$ & 0.53 & $/$ & $/$ \\
\hline
\end{tabular}

3.4. MSME. By virtue of its distinct structure and broad $T_{\text {trans, }}$, the 1024-layer specimen was chosen for investigation of its MSME potential. The thermomechanical programming for the triple-shape memory test is depicted in Figure S2. The specimen was firstly stretched at $\mathrm{T}_{1}\left(115^{\circ} \mathrm{C}\right)$, and then fixed at $\mathrm{T}_{2}\left(60,65\right.$ or $\left.70^{\circ} \mathrm{C}\right)$. The second deformation was conducted at $\mathrm{T}_{2}$ and then fixed at $\mathrm{T}_{3}\left(30^{\circ} \mathrm{C}\right)$. After that, a free strain recovery was carried out gradually by reheating the specimen to $T_{2}$ and $T_{1}$, respectively. The evolution of temperature, strain and stress during the process for 1024-layer specimen is shown in Figure 6a-c, and the corresponding $R_{f}$ and $R_{r}$ values in triple shape memory cycles are listed in Table 3. It should be noted that different switching temperatures could be chosen freely from the broad glass transition range to achieve a tunable triple-shape memory effect (TSME). As the interval between the two different deformation temperatures (i.e. $\mathrm{T}_{1}-\mathrm{T}_{2}$ ) increased, the TSME performance of the material improved. When $\mathrm{T}_{2}$ was chosen at $60{ }^{\circ} \mathrm{C}$, the $\mathrm{R}_{\mathrm{f}}$ of two temporary shapes exceeded $90 \%$ for each shape and the $\mathrm{R}_{\mathrm{r}}$ could be maintained above $80 \%$. This means an appropriate temperature interval may not only freeze the segments to hold the temporary shapes but also store enough energy to contribute to recovery. For 
comparison, the PVDF/PMMA blend with the same compositions was prepared by using conventional extrusion technology and its triple-shape memory performance $\left(\mathrm{T}_{1}=115^{\circ} \mathrm{C}, \mathrm{T}_{2}=60^{\circ} \mathrm{C}\right)$ was displayed Figure 6d. Under the same testing conditions, the related $R_{f}$ and $R_{r}$ values of the blend was far away to catch up with that of the 1024-layer specimen, although they owned a similar broadness of $\mathrm{T}_{\mathrm{g}}$ range.

(a)

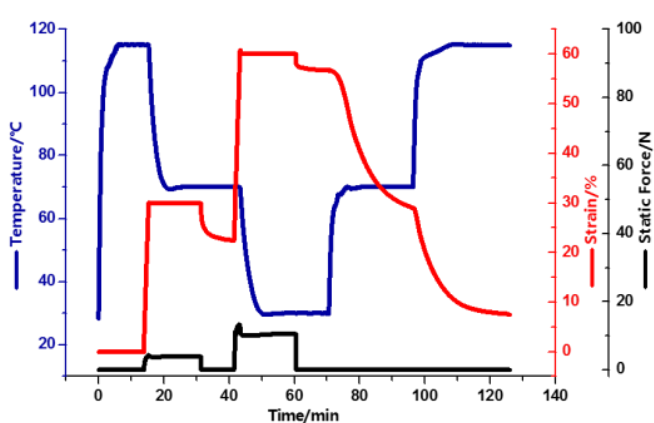

(c)

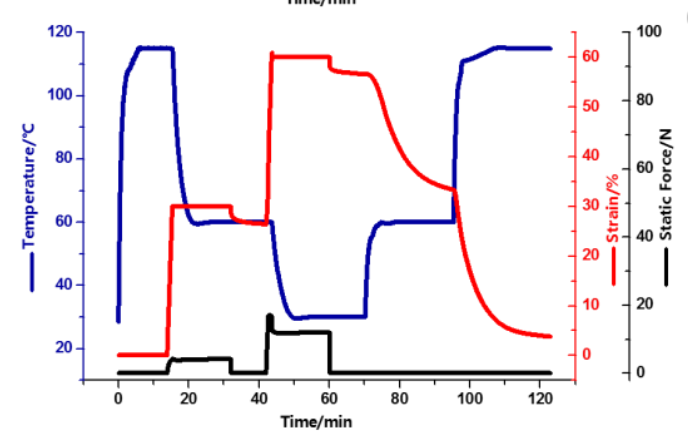

(b)

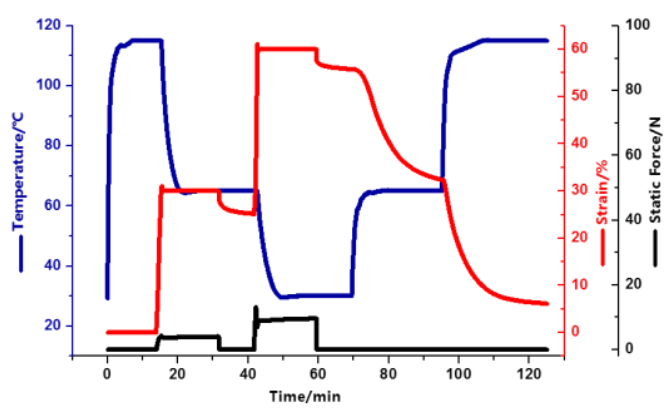

(d)

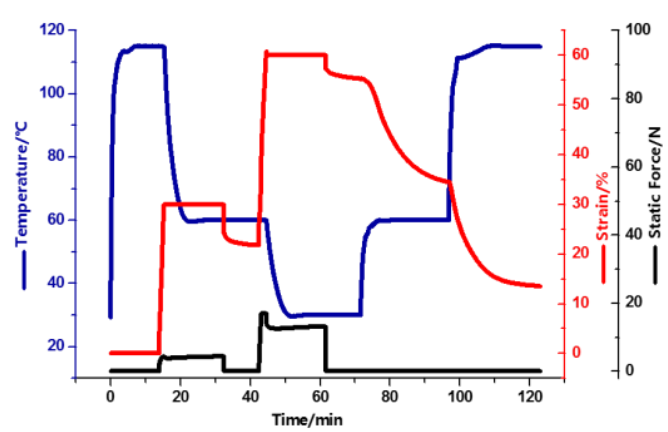

Figure 6. Evolution of strain, stress, and temperature during triple-shape memory cycles for the 1024-layer specimen with switching temperatures of (a) 115 and $70^{\circ} \mathrm{C}$, (b) 115 and $65^{\circ} \mathrm{C}$, (c) 115 and $60^{\circ} \mathrm{C}$; and (d) for the blend specimen with switching temperatures of 115 and $60^{\circ} \mathrm{C}$.

Table 3. The $R_{f}$ and $R_{r}$ of the PVDF/PMMA 1024-layer and blend specimens at each stage (the process is depicted in Figure S2) as a function of switch temperature in the triple-shape memory progress. 


\begin{tabular}{ccccccc}
\hline Sample & $\mathrm{T}_{1}\left({ }^{\circ} \mathrm{C}\right)$ & $\mathrm{T}_{2}\left({ }^{\circ} \mathrm{C}\right)$ & $\mathrm{R}_{\mathrm{f}}(\mathrm{A} \rightarrow \mathrm{B})$ & $\mathrm{R}_{\mathrm{f}}(\mathrm{B} \rightarrow \mathrm{C})$ & $\mathrm{R}_{\mathrm{r}}\left(\mathrm{C} \rightarrow \mathrm{B}_{1}\right)$ & $\mathrm{R}_{\mathrm{r}}\left(\mathrm{B}_{1} \rightarrow \mathrm{A}_{1}\right)$ \\
\hline \multirow{3}{*}{ 1024-layer } & 115 & 70 & $(76.9 \pm 1.3) \%$ & $(95.3 \pm 1.1) \%$ & $(85.1 \pm 0.6) \%$ & $(66.4 \pm 0.9) \%$ \\
& 115 & 65 & $(85.4 \pm 1.4) \%$ & $(92.7 \pm 0.8) \%$ & $(83.6 \pm 0.5) \%$ & $(76.1 \pm 1.0) \%$ \\
& 115 & 60 & $(91.2 \pm 1.1) \%$ & $(90.7 \pm 0.4) \%$ & $(80.8 \pm 0.8) \%$ & $(88.5 \pm 1.2) \%$ \\
Blend & 115 & 60 & $(75.8 \pm 1.0) \%$ & $(88.4 \pm 0.9) \%$ & $(62.8 \pm 0.6) \%$ & $(34.4 \pm 1.5) \%$ \\
\hline
\end{tabular}

Beyond the TSME, the quadruple-shape memory effect (QSME) of the 1024-layer and blend specimens were further concerned. The switching temperatures were chosen at 120,90 and $60^{\circ} \mathrm{C}$ and the totally deformation ratio was maintained at 60\%. As demonstrated in Figure 7a, the 1024-layer specimen could memorize as many as three distinct temporary shapes in a quadruple-shape memory cycle. The $\mathrm{R}_{\mathrm{f}}$ of the first one temporary shape was $73 \%$ and the other two were around $85 \%$. With regard to the shape recoverability, both the $R_{r}$ values of the first two permanent shapes exceeded $87 \%$ and only the last one was below $80 \%$, which was less reported in physically-compounding systems and even comparable to some of synthetic copolymers. Herein, the PVDF/PMMA blend was also chosen to give an example of a contrast. It can be noted from Figure $7 b$ that both the $R_{f}$ and $R_{r}$ were far below those of the multilayer specimen. Particularly, the irreversible strain of the last permanent shape was $10 \%$ which was basically equal to that obtained in the first temporary shape. This indicates that the blend system could not memorize more than two temporary shapes, which should be one of possible reasons that very few melt-blended materials were reported to have good QSME. Furthermore, Figure 7c presents the quadruple-shape memory progress of the 1024-layer specimen recorded by a digital camera. The original shape was gradually deformed to "M" at 120,90 and $60^{\circ} \mathrm{C}$, 
matching with the programming steps performed by DMA instrument. Then the temporary shape was recovered at 60,90 and $120^{\circ} \mathrm{C}$, respectively. It can be observed that the multilayer specimen almost recovered back to the original shape and exhibited a promising application in meeting complex requirements of smart devices, which was previously recognized as a big challenge to physically compounding polymeric systems.
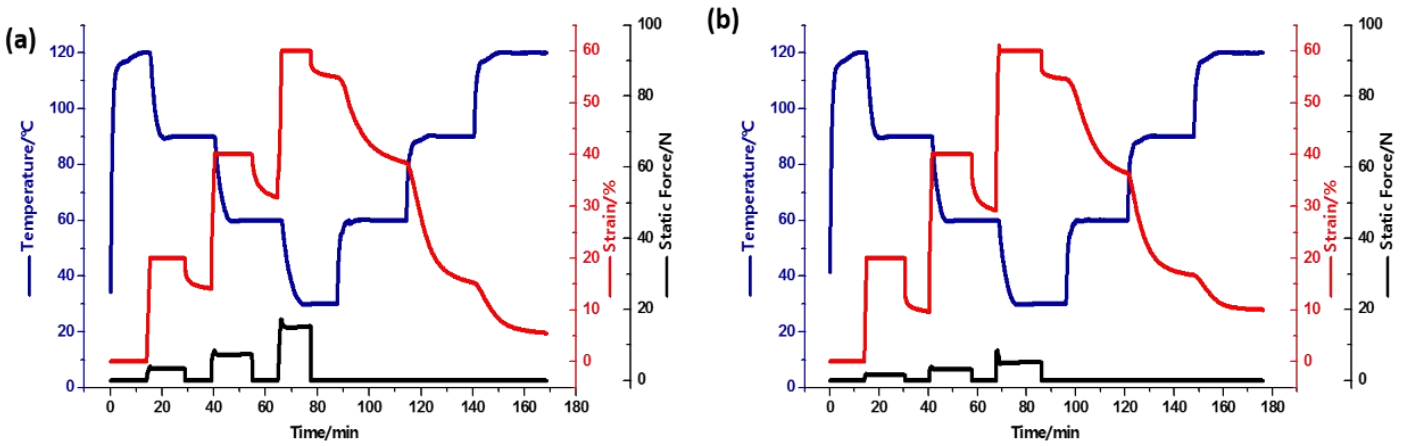

(c)
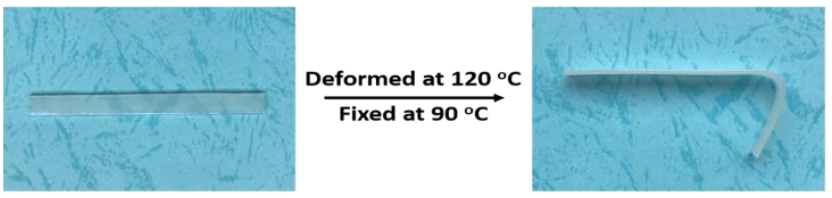

\section{Deformed at $90^{\circ} \mathrm{C}$} Fixed at $60^{\circ} \mathrm{C}$
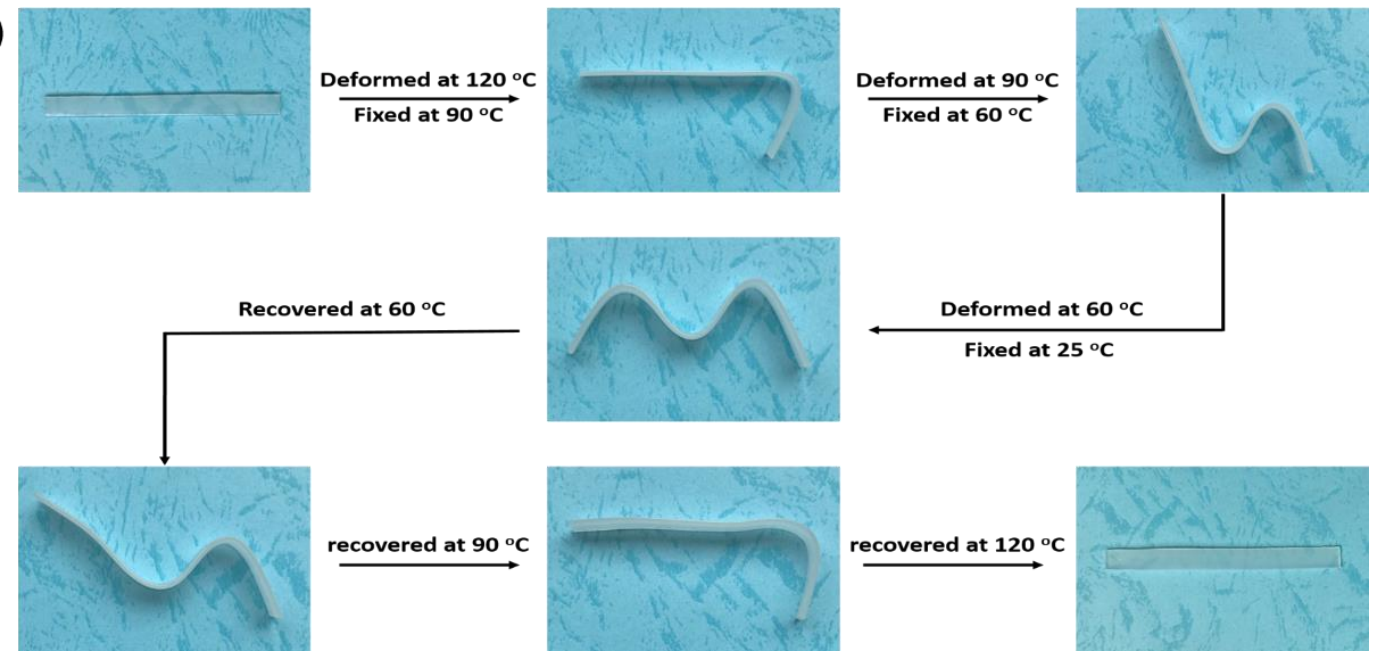

recovered at $120^{\circ} \mathrm{C}$

Figure 7. Evolution of strain, stress, and temperature during a quadruple-shape memory cycle with the switching temperatures of 120,90 and $60{ }^{\circ} \mathrm{C}$ for (a) 1024-layer specimen and (b) the blend specimen; (c) The quadruple-shape memory progress of the 1024-layer specimen recorded by a digital camera. 
3.5. Mechanisms. Above results strongly substantiate that an outstanding MSME may not only require a broad $\mathrm{T}_{\text {trans }}$ range, but also depend on an optimal phase morphology. The microstructure of the blending and multilayer systems is schematically illustrated in Figure 8a. The PVDF and PMMA in the multilayer system are assembled in parallel. Although the blending system can also be divided into many parallel layers, the components in each layer are regarded to be assembled in series. Hence, the different phase continuity may play a significant role in each shape memory process.

In the shape-fixing stage, a specimen would be thermally stretched at a specific temperature, so that the molecular chains tended to be aligned along the deforming direction. Taking this into account, both the blend and 1024-layer specimens were chosen to experience the same thermal stretching process at $115{ }^{\circ} \mathrm{C}$ which corresponds to the maximum temperature used in triple-shape memory process, and then be quickly quenched to $25{ }^{\circ} \mathrm{C}$. To evaluate the orientation degree of molecule chains remained in each specimen, the polarized FTIR was conducted to collect the infrared spectra parallel and perpendicular to the deforming direction by rotating the wire-grid polarizer to 0 and $90^{\circ}$. The spectra in the range of $570-1800 \mathrm{~cm}^{-1}$ are compared in Figure 8b. The absorbance band around $615 \mathrm{~cm}^{-1}$ exhibiting obvious infrared dichroism was chosen to calculate the Herman orientation function (f) according to Eq. (3) and (4). The calculated results were inserted in above figure. For the 1024-layer specimen, its $f$ value $(0.25)$ was larger than that of the blend (0.17), which means more orientation could be obtained in the multilayer system when frozen 
to a low temperature. According to previous studies, $[17,38]$ the parallel-organized components were regarded to be capable of maximizing their contribution to the mechanical deformation. Hence, the system with a high phase continuity should benefit for promoting the orientation of molecular chains which would act as mechanical support for maintaining a temporary shape in the shape-fixing stage. Inversely, when the specimens were reheated to a switching temperature, their stored elastic energy would transform into kinetic energy triggering the recovery of temporary shape. Based on the classic viscoelastic theory,[39, 40] the parallel-assembled components should have the same strain in the recovery process, so that they would be promoted each other through the interfacial shearing effect. However, the components assembled in series receive the same stress along the deforming direction, thus the strain of each component is mainly determined by its own viscoelastic behaviors and less influenced by another component. This implies that more irreversible deformation may be maintained in the blend than that in the multilayer system, which can be further demonstrated through a creep experiment. A constant external force was first hold on both the blend and 1024-layer specimens for 40min at $80{ }^{\circ} \mathrm{C}$ and then unloaded immediately. During this process, the deforming strain of each specimen was recorded and exhibited in Figure 8c. It is clearly shown that a much larger deformation took place in the blend at the creeping stage but less than half of the strain was recovered after $70 \mathrm{~min}$. In contrast, only $22 \%$ strain was finally remained in the 1024-layer specimen after experiencing the same period. This signifies that less irreversible deformation might occur in the multilayer system, 
which was regarded as the critical reason for obtaining a larger $\mathrm{R}_{\mathrm{r}}$ during the shape memory process. Accordingly, the multilayer assembly reported in this work is reasonably considered to open another door to fabricate high-performance MSMPs for meeting the complex demands in smart applications.
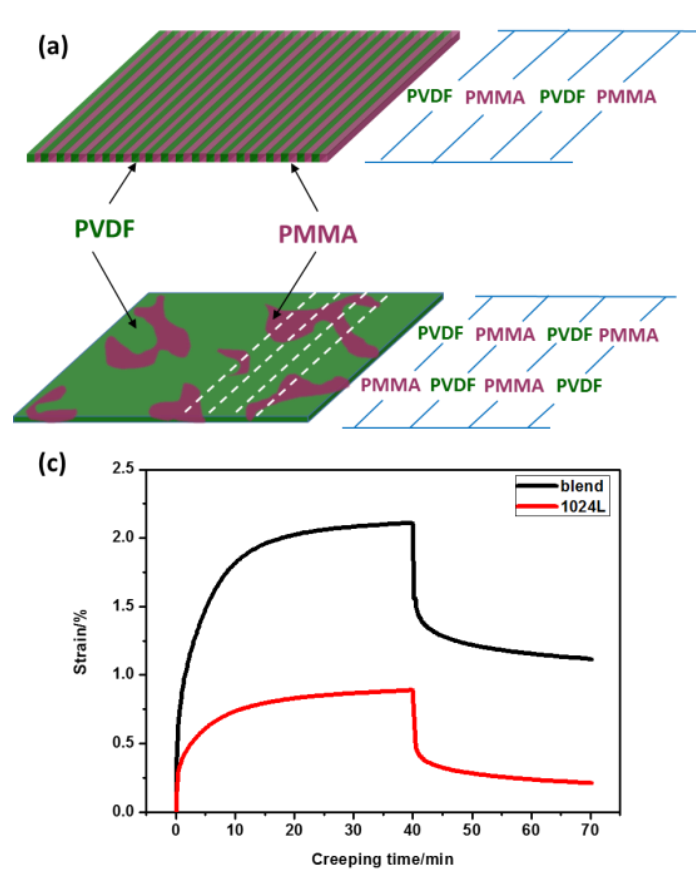

(b)
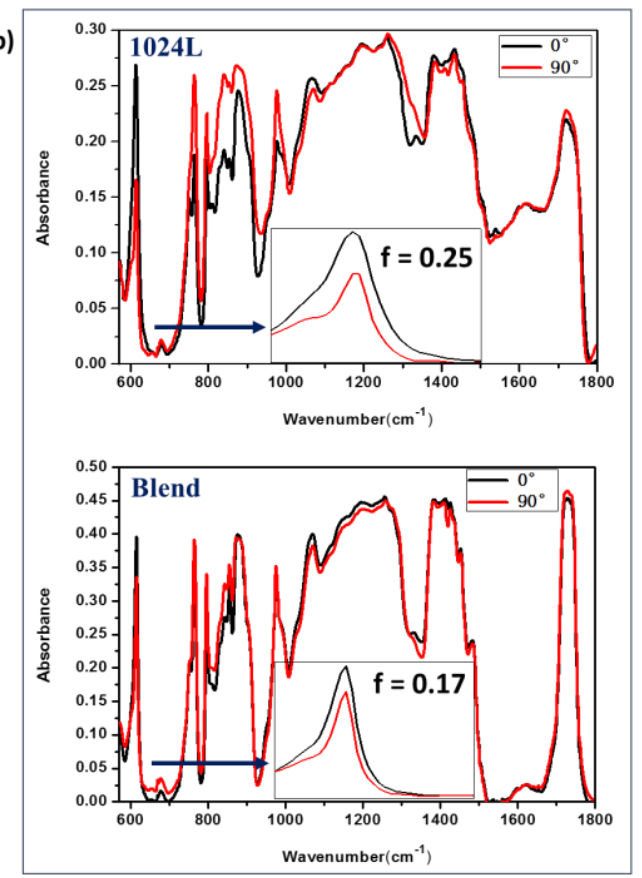

Figure 8. (a) Schematic microstructure of the 1024-layer and the blend specimens; (b)

Polarized FTIR spectroscopy in the range of $570-1800 \mathrm{~cm}^{-1}$ measured at $0^{\circ}$ (parallel to the deforming direction) and $90^{\circ}$ (perpendicular to the deforming direction) for 1024-layer and the blend specimens (both of the specimens are deformed at $115^{\circ} \mathrm{C}$ and then fixed at $25^{\circ} \mathrm{C}$; the inserted figure is the enlarged image of the peak around $615 \mathrm{~cm}^{-1}$ ); (c) Creep curves of the 1024-layer specimen and the blend specimen.

\section{CONCLUSIONS}

An effective physically-compounding strategy for fabricating alternately-organized multilayer structure was introduced to achieve outstanding 
MSME. By virtue of good compatibility between PVDF and PMMA, their molecular chains could diffuse into each other at layer interfaces. Therefore, a broader and more continuous $\mathrm{T}_{\text {trans }}$ range from PVDF to PMMA layers was generated with the multiplication of layers. The low- $\mathrm{T}_{\text {trans }}$ side originated from the glass transition of PMMA. When the layer numbers were increased from 16 to 1024 , the $\mathrm{T}_{\mathrm{g}, \mathrm{PMMA}}$ was reduced from 121 to $86{ }^{\circ} \mathrm{C}$ and the $\mathrm{FWHM}$ was expanded by $37{ }^{\circ} \mathrm{C}$. It was demonstrated that the plasticization effect of non-crystalline PVDF chains broadened the relaxation distribution of amorphous chains of PMMA. On the other hand, the high- $T_{\text {trans }}$ side was dominated by the melting of PVDF crystals. The compositional diffusion strengthened the interaction between amorphous and crystalline domains leading to the reduction of crystallization degree and lamellar thickness. Such a unique multilayer network, where the crystals in PVDF layers with a higher $\mathrm{T}_{\text {trans }}$ acting as physical networks connected the neighboring amorphous layers with a lower $\mathrm{T}_{\text {trans, }}$ was regarded to be beneficial to achieve MSME. In comparison to the conventional melt blend possessing the same compositions and a similar $\mathrm{T}_{\text {trans }}$ range, the 1024-layer specimen had a better TSME and even could successively memorize as many as three shapes in a quadruple-shape memory progress. Higher phase continuity as another important factor which benefited for the stress transfer was substantiated to play a significant role in strengthening the shape-fixing and -recovering ability during each shape-memory cycle. Accordingly, the multilayer assembly was believed as a promising physically-compounding strategy for fabricating a new kind of MSMPs with high phase continuity and tunable thermal transition to meet the applications in 
complex conditions.

\section{Supporting Information}

The Supporting Information is available free of charge on the website.

\section{Corresponding Author}

* E-mail address: shenjb@scu.edu.cn (Jiabin Shen)

\section{Acknowledgements}

The authors are grateful to the National Natural Science Foundation of China $(51873132,51673136,51420105004,51721091)$ for financial support of this work.

\section{Notes}

The authors declare no conflict of interest. 


\section{References}

[1] M.D. Hager, S. Bode, C. Weber, U.S. Schubert, Shape memory polymers: Past, present and future developments, Prog. Polym. Sci., 49-50 (2015) 3-33.

[2] J. Hu, Y. Zhu, H. Huang, J. Lu, Recent advances in shape-memory polymers: Structure, mechanism, functionality, modeling and applications, Polym. Sci., 37 (2012) 1720-1763.

[3] M. Behl, M.Y. Razzaq, A. Lendlein, Multifunctional shape-memory polymers, Adv. Mater., 22 (2010) 3388-3410.

[4] A. Lendlein and R. Langer, Biodegradable, Elastic Shape-Memory Polymers for Potential Biomedical Applications, Science, 296 (2002) 1673-1676.

[5] Y. Liu, H. Du, L. Liu, J. Leng, Shape memory polymers and their composites in aerospace applications: a review, Smart Mater. Struct., 23 (2014) 023001.

[6] L. Santo, F. Quadrini, A. Accettura, W. Villadei, Shape Memory Composites for Self-deployable Structures in Aerospace Applications, Procedia Eng., 88 (2014) 42-47.

[7] I. Bellin, S. Kelch, R. Langer, A. Lendlein, Polymeric triple-shape materials, Proc. Natl. Acad. Sci., 103 (2006) 18043-18047.

[8] T. Xie, X. Xiao, Y.T. Cheng, Revealing triple-shape memory effect by polymer bilayers, Macromol. Rapid. Commun., 30 (2009) 1823-1827.

[9] J. Zotzmann, M. Behl, Y. Feng, A. Lendlein, Copolymer Networks Based on Poly( $\omega$-pentadecalactone) and Poly( $\epsilon$-caprolactone)Segments as a Versatile Triple-Shape Polymer System, Adv. Funct. Mater., 20 (2010) 3583-3594.

[10] Y. Zheng, X. Ji, M. Yin, J. Shen, S. Guo, Strategy for Fabricating Multiple-Shape-Memory Polymeric Materials via the Multilayer Assembly of Co-Continuous Blends, ACS Appl. Mater. Interfaces, 9 (2017) 32270-32279.

[11] S.K. Ahn, R.M. Kasi, Exploiting Microphase-Separated Morphologies of Side-Chain Liquid Crystalline Polymer Networks for Triple Shape Memory Properties, Adv. Funct. Mater., 21 (2011) 4543-4549.

[12] T. Xie, Tunable polymer multi-shape memory effect, Nature, 464 (2010) 267-270.

[13] L. Wang, X. Yang, H. Chen, G. Yang, T. Gong, W. Li, S. Zhou, Multi-stimuli sensitive shape memory poly(vinyl alcohol)-graft-polyurethane, Polymer Chemistry, 4 (2013) 4461.

[14] Y. Luo, Y. Guo, X. Gao, B.G. Li, T. Xie, A general approach towards thermoplastic multishape-memory polymers via sequence structure design, Adv. Mater., 25 (2013) 743-748.

[15] K. Kratz, S.A. Madbouly, W. Wagermaier, A. Lendlein, Temperature-memory polymer networks with crystallizable controlling units, Adv. Mater., 23 (2011) 4058-4062.

[16] C. Samuel, S. Barrau, J.-M. Lefebvre, J.-M. Raquez, P. Dubois, Designing Multiple-Shape Memory Polymers with Miscible Polymer Blends: Evidence and Origins of a Triple-Shape Memory Effect for Miscible PLLA/PMMA Blends, Macromolecules, 47 (2014) 6791-6803.

[17] Y. Zheng, R. Dong, J. Shen, S. Guo, Tunable Shape Memory Performances via 
Multilayer Assembly of Thermoplastic Polyurethane and Polycaprolactone, ACS Appl. Mater. Interfaces, 8 (2016) 1371-1380.

[18] Y. Zheng, X. Ji, Q. Wang, J. Shen, S. Guo, Structural design of polyurethane/poly(butylene succinate)/polycaprolactone compounds via a multilayer-assembled strategy: achieving tunable triple-shape memory performances, RSC Adv., 8 (2018) 42337-42345.

[19] F. Zhang, G. He, K. Xu, H. Wu, S. Guo, The damping and flame-retardant properties of poly(vinyl chloride)/chlorinated butyl rubber multilayered composites, J. Appl. Polym. Sci., 132 (2015).

[20] D. Wang, H. Zhang, J. Guo, B. Cheng, Y. Cao, S. Lu, N. Zhao, J. Xu, Biomimetic Gradient Polymers with Enhanced Damping Capacities, Macromol. Rapid. Commun., 37 (2016) 655-661.

[21] W. Gao, Y. Zheng, J. Shen, S. Guo, Electrical properties of polypropylene-based composites controlled by multilayered distribution of conductive particles, ACS Appl. Mater. Interfaces, 7 (2015) 1541-1549.

[22] S. Luo, Y. Zheng, Z. Zheng, H. Wu, J. Shen, S. Guo, Competitive growth of $\alpha$ and $\beta$-transcrystallinity in isotactic polypropylene induced by the multilayered distribution of $\alpha$-nucleating agents: Toward high mechanical performances, Chem. Eng. J., 355 (2019) 710-720.

[23] J. Zhu, J. Shen, S. Guo, H.-J. Sue, Confined distribution of conductive particles in polyvinylidene fluoride-based multilayered dielectrics: Toward high permittivity and breakdown strength, Carbon, 84 (2015) 355-364.

[24] L. Yi, S. Luo, J. Shen, S. Guo, H.-J. Sue, Bioinspired Polylactide Based on the Multilayer Assembly of Shish-Kebab Structure: A Strategy for Achieving Balanced Performances, ACS Sustainable Chem. Eng., 5 (2017) 3063-3073.

[25] B. Chen, W. Gao, J. Shen, S. Guo, The multilayered distribution of intumescent flame retardants and its influence on the fire and mechanical properties of polypropylene, Compos. Sci. Technol., 93 (2014) 54-60.

[26] S.J. Kang, Y.J. Park, I. Bae, K.J. Kim, H. C. Kim, S. Bauer, E.L. Thomas, C. Park, Printable Ferroelectric PVDF/PMMA Blend Films with Ultralow Roughness for Low Voltage Non-Volatile Polymer Memory, Adv. Funct. Mater., 19 (2009) 2812-2818.

[27] N. Ochoa, M. Masuelli and J. Marchese, Effect of hydrophilicity on fouling of an emulsified oil wastewater with PVDF/PMMA membranes, J. Membr. Sci., 226 (2003) 203-211.

[28] J. Mijovic, J.-W. Sy and T. Kwei, Reorientational Dynamics of Dipoles in Poly(vinylidene fluoride)/Poly(methyl methacrylate) (PVDF/PMMA) Blends by Dielectric Spectroscopy, Macromolecules, 30 (1997) 3042-3050.

[29] J. Duvigneau, H. Schönherr and G. J. Vancso, Nanoscale Thermal AFM of Polymers: Transient Heat Flow Effects, ACS nano, 4 (2010) 6932-6940.

[30] T. Eby, U.Gundusharma, M. Lo, K. Sahagian, C. Marcott and K. Kjoller, Reverse engineering of polymeric multilayers using AFM-based nanoscale IR spectroscopy and thermal analysis Spectrosc. Eur., 24 (2012) 18-21.

[31] B. Hahn, J. Wendorff and D. Y. Yoon, Dielectric Relaxation of the Crystal-Amorphous Interphase in Poly(vinylidene fluoride) and Its Blends with 
Poly(methyl methacrylate), Macromolecules, 18 (1995) 718-721.

[32] P. Atorngitjawat, J. Runt, Dynamics of sulfonated polystyrene ionomers using broadband dielectric spectroscopy, Macromolecules, 39 (2006) 1815-1820.

[33] M. Sharma, G. Madras, S. Bose, Unusual Fragility and Cooperativity in Glass-Forming and Crystalline PVDF/PMMA Blends in the Presence of Multiwall Carbon Nanotubes, Macromolecules, 48 (2015) 2740-2750.

[34] Y. Zhang, M. Zuo, Y. Song, X. Yan, Q. Zheng, Dynamic rheology and dielectric relaxation of poly(vinylidene fluoride)/poly(methyl methacrylate) blends, Compos. Sci. Technol., 106 (2015) 39-46.

[35] Z. M. Dang, J. K. Yuan, J. W. Zha, T. Zhou, S. T. Li, G. H. Hu, Fundamentals, processes and applications of high-permittivity polymer-matrix composites, Prog. Mater. Sci., 57 (2012) 660-723.

[36] H. Saito and B. Stuehn, Exclusion of Noncrystalline Polymer from the Interlamellar Region in Poly(vinylidene fluoride)/Poly(methyl methacrylate) Blends, Macromolecules, 27 (1994) 216-218.

[37] Y. Okabe, H. Murakami, N. Osaka, H. Saito, T. Inoue, Morphology development and exclusion of noncrystalline polymer during crystallization in PVDF/PMMA blends, Polymer, 51 (2010) 1494-1500.

[38] K. Yu, Q. Ge, H.J. Qi, Reduced time as a unified parameter determining fixity and free recovery of shape memory polymers, Nat. Commun. 5 (2014) 3066.

[39] H.A. Khonakdar, S.H. Jafari, S. Rasouli, J. Morshedian, H. Abedini, Investigation and Modeling of Temperature Dependence Recovery Behavior of Shape-Memory Crosslinked Polyethylene, Macromol. Theory Simul., 16 (2007) 43-52.

[40] J. Morshedian, H.A. Khonakdar, S. Rasouli, Modeling of Shape Memory Induction and Recovery in Heat-Shrinkable Polymers, Macromol. Theory Simul., 14 (2005) 428-434. 